\section{Los desplazamientos del ocio}

Mauricio Baros Profesor, Pontificia Universidad Católica de Chile y Universidad de Chile
La historia de lo que hoy conocemos como ocio está ligada a determinadas etapas de la vida de los seres humanos. Es así como las diferentes culturas y religiones han dado mayores o menores libertades a sus fieles; eso ha desencadenado modos y tiempos para llevar a cabo las actividades ligadas al pasatiempo en la ciudad.

PLACERES REGULADOS Y PLACERES TOLERADOS / La existencia del ocio ha estado siempre ligada a los discursos de poder; su administración y regulación ha sido algo que siempre se han disputado las elites o poderes gobernantes, es decir, el ocio ha sido siempre una preocupación para los gobiernos de turno, preocupación en el sentido de tener que pensar qué hacer con el ocio de los demás y cómo ocupar el tiempo de los otros.

"We owe our concept of leisure to the people who, long before the Industrial Revolution, were obsessed with making others work." 1 (Burke, 1995)

Una de las mayores preocupaciones de las distintas elites o entes gobernantes ha sido la determinación de estos límites del ocio. Así la historia del ocio no fue sino la historia de un continuo control y delimitación cada vez más creciente del tiempo del ocio.

Estos límites han sido de diverso orden; van desde regulaciones legales, políticas, simbólicas, morales, técnicas, urbanas y arquitectónicas, y se instauran en todos los niveles posibles de la vida cotidiana. La mayor problemática fue que hay una parte del ocio que parece siempre escapar a estos constreñimientos; parece instalarse en dos niveles, un nivel constituye la parte más formal, exterior y regulable - la parte más próxima al negocio- y otra externa de límites imprecisos, que parece siempre situarse en la frontera exterior de toda regulación y reglamento. Es esta la que siempre parece estar desplazándose y escapando de toda regulación. Para examinar estas dos caras se estudian algunos momentos particulares que reflejan la aparición del ocio en dos momentos diferentes de nuestra historia. Uno de ellos es cómo se entendió el ocio en la ciudad colonial hispanoamericana y, el segundo, la situación coyuntural del s. xIx, desde donde nace nuestra concepción contemporánea de ocio.

EL OCIO CONTEMPLATIVO Y LA VILLA / La distinción entre lo que se entiende como ocio personal y ocio de los otros es algo que ha estado presente desde la institucionalización del ocio en el época grecorromana. Fueron griegos y romanos quienes tempranamente separaron lo que consideran la vita activa de la vita contemplativa. La vita activa era la vida política, pues la polis constituía el soporte perfecto para tal actividad, pero no sólo en el sentido simbólico, sino además en el sentido físico, es decir, que el ocio o vita contemplativa - como ellos lo entendían - no cabía dentro del marco de la polis. Es por ello que surge una tipología apta para el otium romano y que es la villa.

"Ha pasado mucho tiempo que no tomo un libro o un lápiz, desde que he conocido las bondades del ocio y del reposo, desde que he disfrutado en breve, de la indolente pero agradable situación de no hacer nada y de ser nada; tanto me han ocupado los negocios de mis amigos que me han impedido disfrutar de los placeres del retiro y la contemplación". (Melmoth, 1809; original de Plinio el joven, c. 62-113 d.C.)
The history of what we know today as leisure is related to determined life stages of human beings. In this way different cultures and religions have given more or less liberties to the faithful; this has triggered methods and times to partake in activities related to the hobby in the city.

El retiro que permitían las villas, situadas por supuesto fuera de la ciudad, es el que posibilitaba el anhelado tiempo de ocio. Pues el ocio es algo que siempre se ha dado en un tiempo y en un espacio bien definido.

"The Italian custom of villeggiatura - whether it should be viewed as a Renaissance revival or as a simple survival of the habits of ancient Romans - spread to the elites of other parts of Europe, from Amsterdam to London. The villa came increasingly to be viewed as the site for leisure activities, especially in the summer." (Burke, 1995)

Tempranamente además surge la clara separación entre el ocio personal y el público o de los demás. Este ocio de las villas era privativo obviamente de las clases señoriales de la época, mientras que el ocio del pueblo era administrado mediante una serie de actividades como el circo, el hipódromo, los teatros y otros -que curiosamente se encontraban dentro del control de la trama urbana-, pues había que evitar lo desmedido, propio de las clases populares que siempre se caracterizan por el desborde. Será entonces en estas primeras urbes que comparecerán estos dos tipos de ocio: uno contemplativo y personal y otro más festivo y público. A partir de este momento la historia del ocio será pendular, es decir, conformada por los vaivenes entre estas dos formas de concebirlo.

EL OCIO Y LA TRAZA URBANA: PLACERES REGULADOS / Recordemos que la polis griega en su génesis es, ante todo, una entidad legal antes que un ente urbano. La generación de la polis significó una inmediata preocupación, entendida como una anticipación de cómo y con qué actividades sería llenada la cuadrícula urbana. Recordemos que el acto de trazar la ciudad estaba cargado de la connotación religiosa separar un pedazo particular del territorio para consagrarlo a una actividad específica, es decir, estaba implícito en el acto de trazar un terreno el darle un destino productivo.

Cuando hablamos que el ocio es algo que siempre ha sido administrado por otros, nos referimos a que así como las regulaciones horarias determinan tanto los tiempos laborales como los de ocio, la traza urbana es su perfecto símil, pues determina una estructura de predios vacíos dispuestos a ser ocupados, es decir, en el acto mismo de trazar está implícito un control tanto de las actividades laborales como del ocio. Lo vemos claramente cuando se analiza la asignación de predios sobre la trama urbana; todas aquellas actividades no productivas quedaban originariamente fuera de esta traza, con ello nos referimos a lo relacionado con la muerte — cementerios — la enfermedad — hospitales - y la desviación —cárceles- - Sin embargo con la constitución de la traza urbana también se establece una actitud ambigua con respecto al ocio. Suelen aparecer dos tipos diferentes de ocio. Primero está el ocio de la periferia, el ocio del mundo que queda fuera de la grilla racional urbana, que en el caso cercano nuestro era el lugar de los guangualies, los arrabales; toda la población indígena, mestiza y negra que no era considerada digna de habitar en la cuadrícula urbana; “(..) había un centro urbano habitado por los españoles y sus sirvientes y una periferia poblada por los indíge- 
1 "Debemos nuestro concepto de ocio a la gente que, mucho antes de la Revolución Industrial, estaba de la Revolución Industrial, estaba
obsesionada con hacer a otros trabajar." (N. del Ed.)

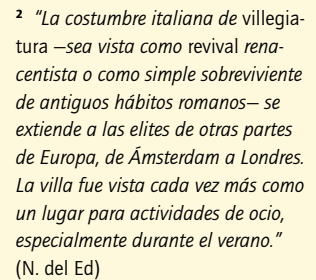

nas, los mestizos y algunos africanos libres asimilados a ellos" (De Ramón, 2000). Este es un ocio que resulta especial y espacialmente interesante pues está asociado al mundo no civilizado, que se caracteriza por ser desmedido y desbocado.

"Todo se suele hacer en medio de grandes banquetes y embriaguez, que es el vicio que más predomina en todos los indios universalmente a la manera que lo hacían los griegos en las fiestas bacanales, llamadas orgía". (Marino de Lovera, 1865)

Esto nos habla inmediatamente de una geografía ambigua del ocio, pues estos lugares, generalmente en los márgenes de la ciudad, quedaban fuera del espacio controlado por la traza urbana. Era en estos espacios de límites imprecisos donde se producía el desborde y la bacanal. Un caso claro y aún existente son las llamadas pampillas, como la descrita por Joaquín Vallejo en el denominado Campo de Marte: "Embebida su atención en la muchedumbre de viajeros de todas clases que alcanza o encuentra por los callejones donde se ha metido, penetra de repente en los suburbios de la ciudad, en esos hormigueros de democracia, que, siempre en gresca i algazara, ofrecen de ordinario a las puertas de la capital, las mismas babeles dominicales de los campos de provincia, en que tienen lugar las partidas de chueca o las carreras de caballos." (Vallejo, 1841-1847).

Eran espacios vacantes, vacíos, abiertos a lo improvisado; de ahí su atractivo popular que aún sigue existiendo en algunos lugares del norte de nuestro país.

Pero para la ciudad docta y regulada estos son lugares que hay que controlar. Junto con el arribo de la industrialización a nuestro país estos lugares serán desplazados nuevamente a los márgenes de la ciudad o aquellos sitios que se constituyen en verdaderas heridas urbanas, lugares que son los residuos de la modernidad, paños urbanos sin destino o retazos de territorio inútiles.

Estos lugares del ocio marginal han convivido siempre con los lugares del ocio festivo, quienes constituyen la cara oficial y permitida del ocio urbano y que tienen su antecedente en la fiesta religiosa.

LA FIESTA RELIGIOSA Y EL OCIO FESTIVO / Las religiones en general no sólo han tendido a practicar un ocio contemplativo sino que además han sido expertas en el manejo de las masas. La iglesia fue uno de los poderes que más prolija y cuidadamente administraron el ocio colonial y para ello se creó un sistema muy sutil y hábil para controlar el ocio urbano. La iglesia supo controlar el tiempo y el espacio a través de dos instrumentos diferentes: el control acústico —que abarca desde una campanada hasta un rezo-y el control espacial mediante la fiesta urbana.

Somos una sociedad acostumbrada a marcar el umbral entre lo laboral y lo no laboral acústicamente antes que visualmente, ya sea a través de la campana de un iglesia, el canto de un gallo, el silbido de un tren, el timbre de un recreo, la alarma del reloj, el sonido del teléfono y otros. Este control acústico se hacía más omnipresente en el mundo colonial, pues desde el tiempo global hasta el tiempo personal transcurrían al ritmo eclesial.

"Le ciel et la conque bleus de la Capitale, furent le théâtre d'une bataille sidérale entre les cloches, civiles et religieuses, grosses ou petites, toutes dominées par la sonorité virbrante de l'Assumpta de la cathédrale."3 (Pereira Salas, 1966)

La importancia de esta marcación temporal obligó a que incluso tuviese que existir, como Pereira Salas señala, un Reglamento de Toque de Campanas promulgado en 1797 por el rey de España a pedido del gobernador de Chile. Por otra parte mientras las campanas normaban el tiempo urbano, a nivel personal el tiempo podía ser medido por un credo o un avemaría.

"Las sirvientas en sus actividades culinarias hacían uso del mismo tipo de control del tiempo: la cocción de un huevo, por ejemplo, era medida y santificada por un Ave María dicho en voz alta." (Pereira Salas, 1966)
Por otra parte la fiesta religiosa era la excusa para la detención de las actividades laborales y el posterior aprovechamiento del tiempo para divertirse.

La fiesta en sí legitimaba la diversión al interior de la ciudad y era la mayor expresión festiva en la cual se podía participar. Es por ello que igualmente se tenía especial cuidado en el control temporal y espacial de estas fiestas, las cuales obedecían un calendario rígidamente establecido y exigían su participación respetando un protocolo previamente instituido. Esto no impedía que en el tiempo posterior a la celebración religiosa se continuase con los festejos en otro sector de la ciudad.

"El que la fiesta ahora sea sinónimo de desenfreno es porque inicialmente la fiesta religiosa, si bien tenia todo un objetivo político y social, era el pretexto para el ocio pues significaba la liberación del tiempo del trabajo." (Marfany, 1997)

Esto además explica por qué antes estas actividades se permitían en los tiempos festivos y no fuera de ello, es decir, ya la fiesta en sí misma como evento plantea el establecimiento de límites temporales y espaciales, donde se debía hacer y donde se permitían estos actos posteriormente condenados. La fiesta daba licencia a estos comportamientos pues en su esencia es una celebración festiva. El problema se presentaba en el control de este ocio festivo con posterioridad a la ceremonia religiosa.

Es precisamente este tiempo posterior a la fiesta, indefinido e incontrolado, el que motivó una nueva regulación del ocio.

"Al tiempo ecuménico, litúrgico y monacal de la Iglesia se superpuso el tiempo civil, municipal, ritmado por los sonidos musicales de las torres de vigilancia y los campanarios de iglesia, tiempos burgueses medidos por la ingeniería mecánica de relojes públicos." (Marfany, 1997)

Es así como vemos que en el espacio urbano logran coexistir estos dos tipos de ocio y su historia no es sino el sucesivo vaivén entre dos polos, el ocioy el negocio, lo público y lo privado, lo contemplativo y lo festivo. Por un lado están quienes lo ejercitan libremente y por otro los sometidos al ocio regulado. Ese otro cuyo ocio debe ser administrado para que no haga abuso de él, en el nivel urbano general es entendido como el trabajador, operario y empleado. En un nivel más íntimo y personal ese otro tradicionalmente ha sido la mujer, pues el control del ocio en el espacio público ha sido eminentemente masculino.

"El lugar de las mujeres en el espacio público siempre fue problemático, por lo menos en el mundo occidental que desde Grecia antigua piensa la ciudadanía y construye la política como núcleo de decisión y poder. Una mujer está siempre fuera de lugar en público." (Perrot, 1997)

La mujer está fuera del lugar público pues su lugar tradicional ha sido en el confinamiento de su hogar. Así como los poderes y elites controlan el ocio urbano, el hombre controla el ocio en el seno de su hogar y es por ello que el s. XIX resulta especialmente atractivo, pues será el momento en que la mujer romperá los tradicionales límites impuestos sobre ella y lo hará curiosamente desde uno de sus momentos de ocio.

TRANSGRESIONES DEL OCIO EN EL S. XIX: NUEVOS DESPLAZAMIENTOS / De la misma manera que las regulaciones laborales históricamente han regulado el tiempo del ocio, la traza urbana ha igualmente controlado los espacios y lugares del ocio. La administración del ocio implica necesariamente un manejo en las técnicas de contención y disciplinamiento no solo de las mentes sino además de los cuerpos. Lo que se produjo a escala urbana se replicó en la escala íntima del hogar.

"Los hombres, de hecho, son los dueños de lo privado y especialmente de la familia, instancia fundamental, cristal de la sociedad civil, que gobiernan y representan 


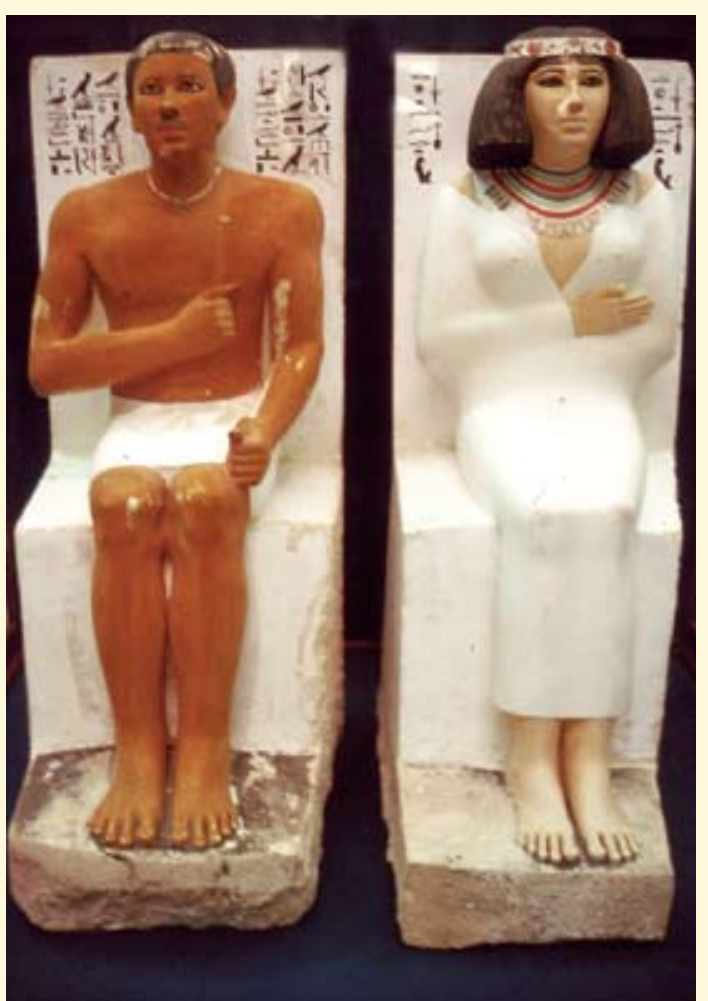

01 Rahotep y Nofret, 2613-2589 a. C. Museo del Cairo. Fuente: Archivo del autor

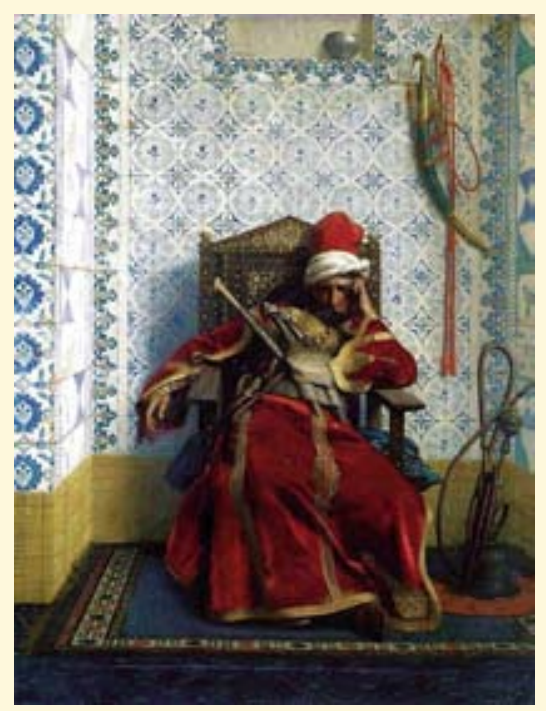

03 Markos Botsaris, Jean-Léon Gerôme, 1874.

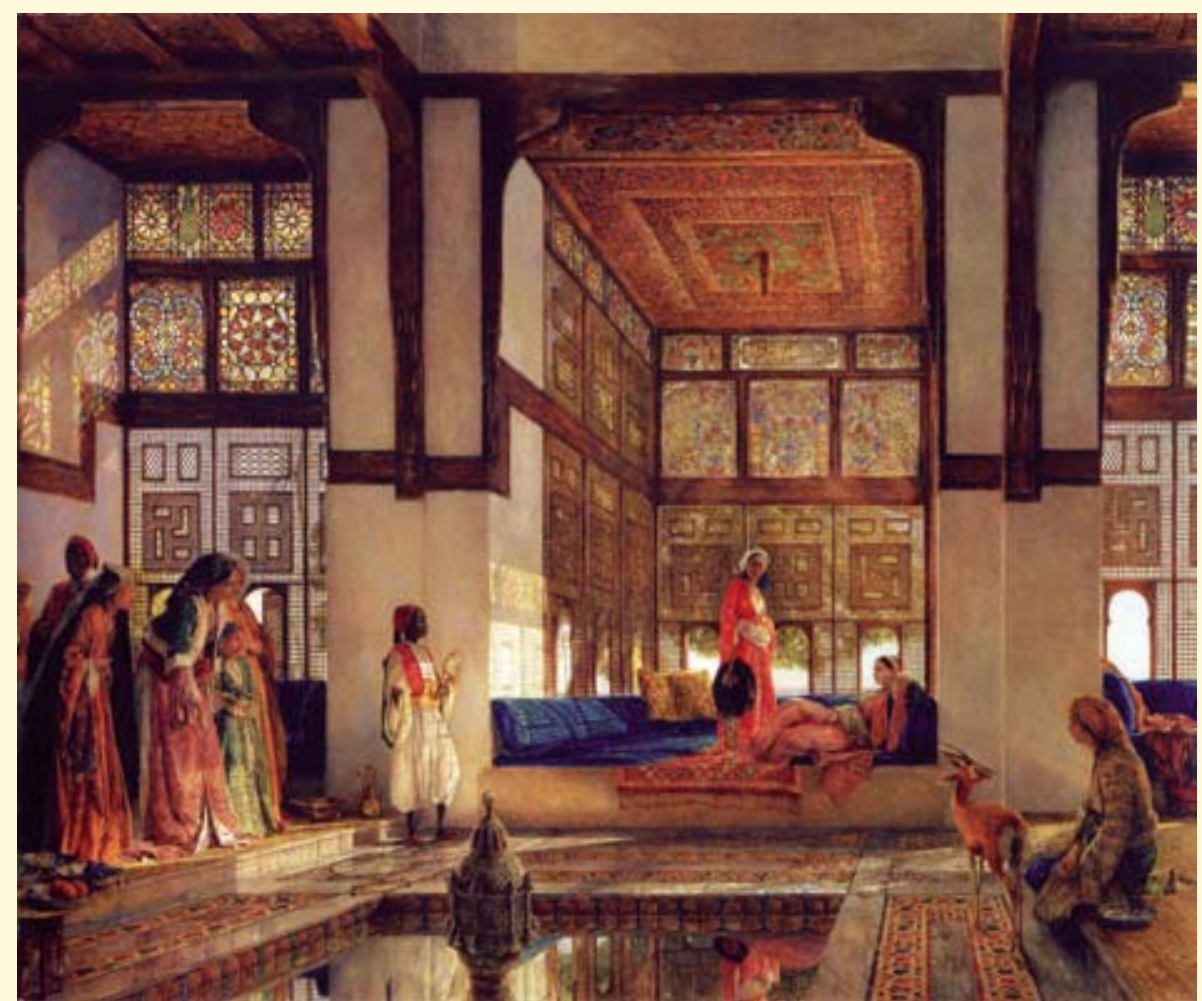

02 John Frederick Lewis, Señora recibiendo visitas (La recepción), 1845-1851. Fuente: The Lure of the East. Tate Publishing, Londres, 2008

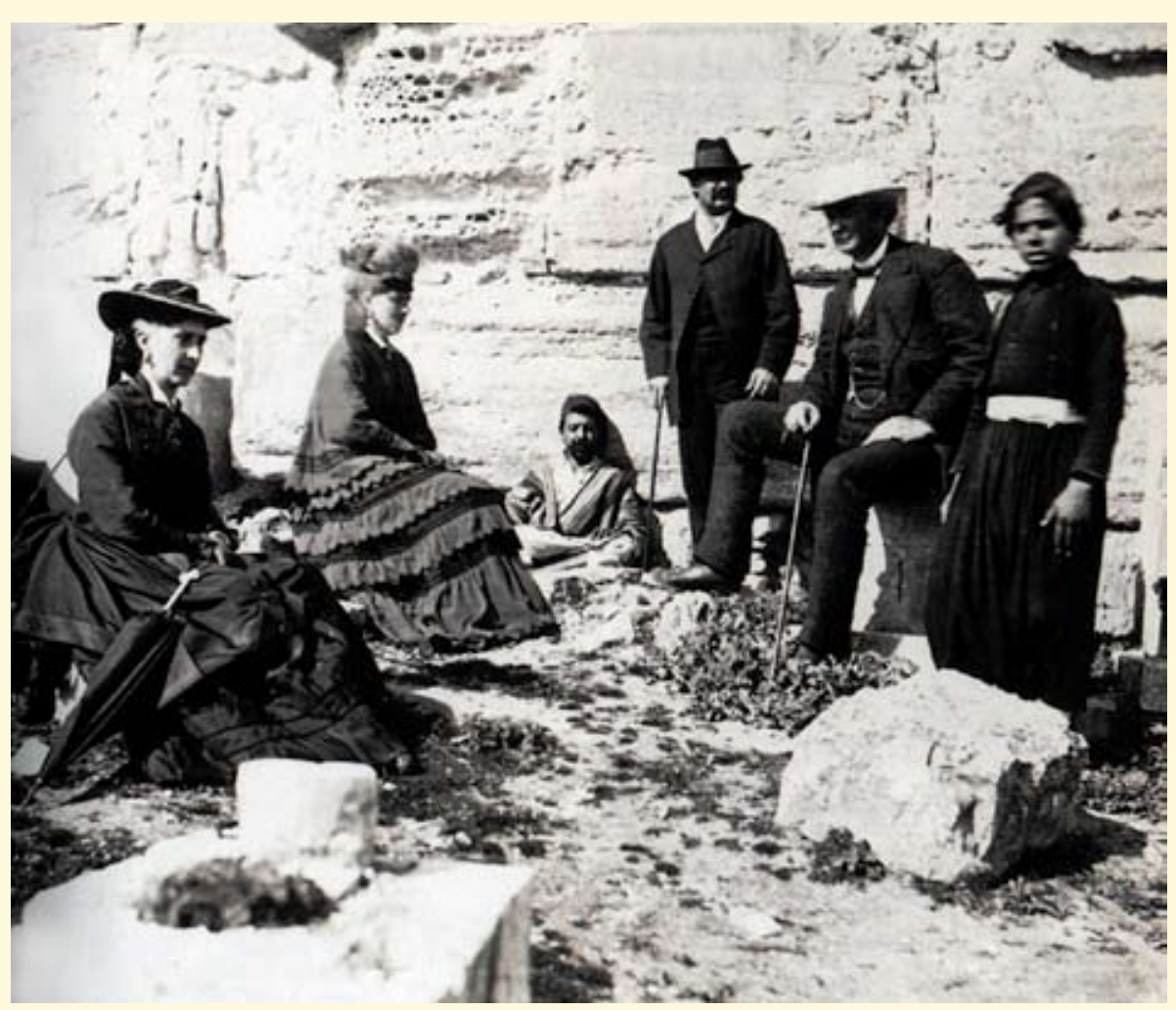

04 Turistas en Jerusalén, 1860-1890. Fuente: Hodgson. Barbara. Dreaming of the East. Greystone Books, Vancouver, 2005 
aunque deleguen, en las mujeres la gestión de lo cotidiano." (Perrot, 1997)

Han existido muchos sujetos a través de la historia que han sido utilizados para representar el ocio, de todos ellos el más universal sin duda ha sido el de la mujer. La representación de la mujer asociada al ocio es tan antigua como el ocio mismo.

Si hiciésemos una lectura retrospectiva podremos ver que a lo largo de la historia se ha construido todo un imaginario respecto de la supuesta inactividad de la mujer que data desde casi los mismos inicios de la civilización. Es una construcción finamente realizada, que parte en la vestimenta misma de la mujer, la cual, a través de pesados ropajes, velos, corsés y otros, ha visto primeramente atrapado su cuerpo. Luego continúan los espacios de confinamiento íntimo a nivel de su propio hogar y que se extienden a edificios públicos y al espacio urbano, donde a través de recursos legales, sociales, morales y religiosos constituyen una verdadera ciudad virtual, cuyos muros son reglamentos, prohibiciones y sanciones de diversa índole que regulan la correcta conducta de la mujer en la ciudad.

\section{"El espacio de la ciudad nunca es sencillo para las mujeres." (Perrot, 1997)}

Ya en el s. xv a.C. vemos a una Nofret atrapada en un ceñido vestido junto a su Rahotep, su marido, en una estatua funeraria del Egipto Antiguo. Su rostro blanco que contrasta con el tostado color de su marido denota que ella no realiza labores en el exterior, pues se mantiene encerrada en su hogar. Su ceñido vestido es claro indicio de su inactividad, pues resulta incómodo para cualquier labor, contrastando con la liviana falda de su esposo. Este apresamiento simbólico de la mujer no es sino un instrumento de posesión espacial de su cuerpo. Demóstenes en el s. iv a.C decía: "Tenemos heteras para nuestro placer, concubinas para servirnos y esposas para el cuidado de nuestra descendencia." (Pomeroy, 1987)

El cuidado y resguardo de la mujer generó toda una arquitectura cuyo principal objetivo fue administrar el ocio de la mujer. Mientras el poder local regulaba el ocio urbano, el hombre lo hacía al interior de su propio hogar.

"La separación física de los dos sexos se llevaba a cabo con especial énfasis en sus respectivos ámbitos espaciales. Mientras los hombres pasaban la mayor parte de su tiempo en lugares públicos como la plaza del mercado y el gimnasio, las mujeres respetables permanecían en sus casas." (Pomeroy, 1987)

Fueron siglos de enclaustramiento en gineceos, matroneos, harenes, conventos, velos y mantos, que mantuvieron el control sobre la actividad de la mujer. Es muy interesante notar entonces que el nacimiento del ocio contemporáneo haya ocurrido en el mismo momento que la mujer se liberara de todas estas ataduras, hecho que no parece ser fortuito, sino que está completamente relacionado, como veremos a continuación.

Es en el s. xix que se produce la principal disrupción a este estado de cosas y la mujer lo realizará nada menos que en sus momentos de ocio. Los instrumentos que utilizará serán la lectura y la escritura.

"La lectura, placer tolerado o conseguido, fue para muchas mujeres un modo de apropiarse del mundo, del universo exótico de los viajes y del universo erótico de los corazones." (Perrot, 1997)

Es justamente en el momento que la mujer está incorporándose activamente al campo laboral que comienza una creciente visualidad del ocio como nunca antes y cuyo principal protagonista será la mujer.

"Hombres ocupados, atareados vestidos de negro, contrastan con mujeres ociosas y entregadas a una mundanidad tan frenética como ritualizada." (Perrot, 1997)

Estas mujeres ociosas romperán, sin embargo, el embrujo de la inactividad a la cual estaban sometidas, a través del rompimiento de las barreras fisicas y simbólicas que les permitió la lectura, que dio pie a la conquista mental de espacios más allá de su confinamiento, con relatos de mundos exóticos y lejanos que les resultaban atrayentes. Fueron ellas las que permitieron romper con las barreras mentales, miedos y prejuicios, para aventurarse en un mundo fuera de las fronteras de lo habitual y lo cotidiano. En segundo lugar su rol de escritora le permitió a la mujer salir al mundo público. Así conquistarán primero este espacio bajo un seudónimo literario, apareciendo posteriormente como figuras reales.

El s. xIx fue un período en que se practicaron estos viajes imaginarios incitados por la lectura y la pintura. No sólo se atravesaban las fronteras de lo civilizado —entiéndase como lo europeo — sino además la mujer estaba cruzando sus propias fronteras sociales. Es por ello que el exotismo y la mujer son sujetos afines en el s. XIX. El primero es producto del romper las barreras del mundo cotidiano europeo, hacia mundos y espacios imaginarios más allá de las fronteras de lo habitual. Esto es lo mismo que estaba haciendo la mujer en su propia escala, rompiendo las barreras del espacio íntimo del hogar en que se mantuvo y, con ello, escapando del poder masculino que la mantenía enclaustrada.

Es en este mismo momento que el mundo europeo, bajo el influjo del puritanismo anglosajón, estará erradicando definitivamente los últimos vestigios de la vida contemplativa, que cada vez será el privilegio de una elite menos numerosa. La nueva ética puritanista asociará este tipo de vida con la acidia y la pereza; es por ello que simbólicamente las representaciones del ocio también se desplazan ahora a un mundo extraeuropeo.

"Puritanism, in its marriage of convenience with industrial capitalism, was the agent which converted men to new valuations of time; which taught children even in their infancy to improve each shining hour; and which saturated men's minds with the equation, time is money"s (Thompson, 1967)

Es así como en un nivel íntimo la mujer desplaza la frontera de sus espacios de ocio al ámbito urbano. A un nivel global, el ocio es desplazado hacia regiones consideradas no civilizadas, alejadas aún del progreso como podían ser Medio Oriente, Lejano Oriente o Latinoamérica.

De aquí nace la idea de asociar el ocio con lugares exóticos. Los límites de la antigua urbe parecen haber crecido, generando una nueva periferia que ahora es global y en donde es posible proyectar el abanico de actividades con que el ocio es asociado, siempre en destinos alejados, pero ahora convenientemente protegidos y preparados para ejercitarlo.

La creciente precisión temporal y espacial entre tiempo útil y espacios del ocio ha permitido crear verdaderos reductos destinados específicamente para este fin, que no son sino una amalgama de elementos del imaginario aludido. Palmeras, arenas y edificios blanqueados son posibles de encontrar en cualquier latitud -los hemos etiquetado como resorts - y nos entregan un ocio encapsulado y garantizado, en donde se busca entregar la idea de un tiempo detenido o suspendido, con entretenciones abiertas las 24 horas del día. Nos dan la ilusoria sensación de una libertad que se perdió hace mucho tiempo, desde que el ocio se convirtió en un negocio. ARQ

\section{Bibliografía}

Burke, Peter. "The Invention of Leisure in Early Modern Europe”. Past \& Present, $\mathrm{N}^{\circ} 146$. Oxford University Press y Past and Present Society, Londres, febrero de 1995. / Colección de los Artículos de don Joaquín Vallejo. Jotabeche 1841 - 1847. Imprenta del Deber, Valparaíso, 1878. / De Ramón, Armando. Santiago de Chile. Editorial Sudamericana, Santiago, 2000. / "L'évolution de la notion du temps et les horlogers à l'époque coloniale au Chili. Eugenio Pereira Salas. Annales". Économies, Sociétés, Civilisations, vol. 21, № 1. París, 1966. / Marfany, Joan-Lluís. "The Invention of Leisure in early Modern Europe”. Past \& Present, $\mathrm{N}^{\circ} 156$. Oxford University Press y Past and Present Society, Londres, agosto de 1997. / Mariño de Lovera, Pedro. "Crónica del Reino de Chile”. Colección Historiadores de Chile y Documentos Relativos a la Historia Nacional, tomo VI. Imprenta del Ferrocarril, Santiago, 1865. / Melmoth, William. The Letters of Pliny the Consul, vol. I-II. Greenough \& Stebbins, Boston, 1809. / Perrot, Michelle. Mujeres en la ciudad. Editorial Andrés Bello, Santiago, 1997. / Pomeroy, Sara. Diosas, rameras, esposas y esclavas. Mujeres en la antigüedad clásica. Akal Universitaria, Madrid, 1987. / Thompson, E. “Time, Work-Discipline and Industrial Capitalism”. Past 8 Present, $\mathrm{N}^{\circ}$ 38. Oxford University Press y Past and Present Society, Londres, diciembre de 1967. 